\title{
Experimental study and modeling of the mechanical behavior of recycled aggregates-based high-strength concrete
}

\author{
Kheira Camellia Nehar \\ Laboratory of Mechanics and Materials Development at the University of Djelfa, POBox 3117, 17000 Djelfa - Algeria \\ camellia90@hotmail.fr,c.nehar@univ-djelfa.dz,,bttps://orcid.org/0000-0002-9188-2496 \\ Dalila Benamara \\ Laboratory of Civil Engineering at the University of Djelfa, POBox 3117, 17000 Djelfa - Algeria \\ benamaradalila2018@gmail.com,d.benamra@univ-djelfa.d₹
}

\begin{abstract}
The concrete constitutes a material of prime importance which is widely used in different works and infrastructures. Among the raw materials component the concrete are the aggregates which take the first place. It is widely acknowledged that the consumption of natural aggregates increases with the growth in the amount of concrete needed. It has recently emerged that concrete waste can be recycled and reused in civil engineering works after a series of treatments. Moreover, in order to protect the environment and based on the principles of sustainable development, it was considered urgent to produce a High Strength Concrete incorporating recycled materials in addition to silica fume and a high-efficiency superplasticizer. This would certainly help to establish a harmonious sustainable development that guaranties the ecological balance and environmental protection, and prevents the depletion of natural resources.

This study is part of a larger research program that that seeks to recover, recycle and valorize construction and demolition wastes. The main objective sought in this article is firstly to use aggregates from demolition concrete in the manufacture of a new concrete with high mechanical and rheological performance, and secondly, to model the behavior of this type of concrete using the Finite Element Method. This modeling aims to evaluate the maximum compressive strengths and compare them with those obtained experimentally.
\end{abstract}

KEYwORDS. High strength concrete; Recycled aggregates; Environment; Modelization; Finite element method.

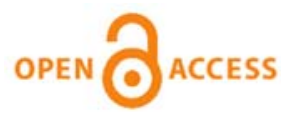

Citation: Nehar, K.C.., Benamara D., Experimental study and modeling of the mechanical behavior of recycled aggregatesbased high-strength concrete, Frattura ed Integrità Strutturale, 56 (2021) 203-216.

Received: 19.01 .2021

Accepted: 18.03 .2021

Published: 01.04.2021

Copyright: (C) 2021 This is an open access article under the terms of the CC-BY 4.0, which permits unrestricted use, distribution, and reproduction in any medium, provided the original author and source are credited. 


\section{INTRODUCTION}

$\mathrm{T}$ he refurbishment and reconstruction of civil engineering works produce enormous amounts of waste every year. Algeria, like many other countries around the world, produces between 20 and 30 million tons of demolition debris per year [1]. Considering the accelerated depletion of building material resources, in addition to the new economic, environmental, and political requirements, it has been necessary to envisage recycling waste building materials with a view to using them as substitute materials to manufacture a new type of concrete. In general, many substitute aggregates have been developed through recycling throughout the world in order to preserve the natural aggregates which are constantly decreasing. The first quality benchmark in this field dates from the Second World War (Nixon, 1977). The two most important and interactive points in these studies are the fields of application of recycled concrete waste and their classification with respect to their quality. Recycled materials, sometimes called secondary materials, are numerous and this is why it has become urgent to classify them according to their characteristics [2]. Various types of recyclable materials are currently used in civil engineering applications. These include, recycled concrete, fly and bottom ash, blastfurnace slag, steel slag, cement kiln dust, silica fume, crushed glass, reclaimed asphalt pavement, and rice husk ash. Reutilization of these recyclable materials is especially beneficial in civil engineering applications that require large volumes of materials. When these waste products are used in place of other conventional materials, natural resources and energy are preserved and expensive and/or potentially harmful waste disposal is avoided.

It has been established that it is no longer required to use high quality elements to manufacture strong and efficient materials.

Nowadays, more and more attention is paid to the choice of materials to be used in the design and construction of these structures. Furthermore, it is no longer necessary to use high quality materials to make a strong and resistant structure, because safety and economic factors do not have the same importance for the different types of structures. Indeed, economic factors (i.e. Supply, demand and market saturation) beside the concept of recycling, which consists of avoiding the exhaustion of supply sources, are now inciting us to revalorize recyclable materials of similar sectors [3]. The previously mentioned factors tend to increasingly encourage the recovery of construction and demolition waste to be recycled in the form of substitute aggregates for the development of new concretes.

Therefore, using recycled products is perfectly justified. In this context, the right approach consists in using the right material for the right purpose under the right conditions [4].

In construction, the demand annually amounts to more than 30 million tons of cubic meters of aggregates. Furthermore, much of the waste from construction sites is increasingly transformed into aggregates to be utilized in the formulation of concrete. It can be predicted that in the future about $4 \%$ of buildings will be destroyed each year, which is expected to generate roughly 1 million of cubic meters of concrete waste [5].

In Algeria, the entire production of concrete in construction and public works is made up only of natural aggregates. Over the past few years, constraints related to the growth in demand for aggregates have surfaced, which incited researchers and practitioners to design and develop new aggregates as alternatives to replace natural aggregates. Moreover, it is worth indicating that demolition or construction materials are being increasingly produced in very large quantities. These wastes are generally used as backfill or discharged to the environment which engenders a very bad impact on the ecosystem [6]. As these new aggregates can be recycled on site, all the expenses and costs associated with the transport of natural aggregates on the one hand, and the disposal of demolition waste, on the other, can be saved, which represents a considerable economic advantage. Consequently, this procedure would contribute to reducing the depletion of natural resources and enhancing the concept of sustainable development.

The valorization and the use of aggregates issues from concrete for the manufacturing of a resistant and an efficient hydraulic concrete would help to extend their current field. To the best of our knowledge, few studies have been carried out to date on the possibility of recycling construction demolition waste in order to formulate a high-strength concrete (HSC). Moreover, not many researchers have tried to numerically model this type of concrete. [7]. For these reasons, we have endeavored to explore the above-mentioned subject in order to provide a deeper insight into the topic of construction waste recovery.

According to some authors, Zhang et al. [8], and Abid et al. [9], the effect of bentonite on mechanical and durability behaviour of both natural aggregates concrete (NAC) and recycled aggregates concrete (RAC) was investigated and compared. Results of testing revealed that with the incorporation of bentonite, RAC showed significant improvement in the durability and strength.

To understand the degradation of mechanical properties of recycled aggregate concrete (RAC) after acid rain exposure, the effect of recycled coarse aggregate (RCA) replacement ratios, the acidity ( $\mathrm{pH}$ value) of the simulated acid rain solution and mineral admixtures on compressive strength and elastic modulus of RAC are investigated in the study of Lu et al. [10]. 
However, several researchers have conducted studies on in the numerical modeling of concrete sections in recent years. Deshpande et al. [11] presented the findings of a study which carried out for modeled compressive strength of concrete using the techniques of Artificial Neural Network (ANN), Model Tree (MT) and Non-linear Regression. The prediction of compressive strength of concrete by data-driven models was used by Khademi et al. [12]. Nitka et Tejchman [13] studied the modelling of the behaviour of plain concrete during uniaxial compression and tension using the discrete element method DEM. An advanced finite element model using the general-purpose FE software ANSYS to simulate the behaviour of the initially damaged concrete beams was studied by Berezoug et al. [14]. Peng et al. [15] have studied the numerical simulation of recycled concrete using convex aggregate model and Base Force Element Method (BFEM), they show this combination can be used for simulating the relationship between microstructure and mechanical properties concrete. The numerical modeling of a circular concrete columns has presented by Havlásek [16] he used the nonlinear finite element simulations which allow for arbitrary loading configuration and the topology into the design process. All these research works have conducted the studies on a numerical modeling of concrete behaviour using various approaches based on software simulations. However, this modeling can be done by using the programming of the finite element method (FEM) theory $[17,18]$. This method is now widely used in the engineering field and which is adopted in this work to model the recycled aggregate concrete [19].

The objective of the present work is, on the one hand, to supply an economical resistant concrete, based on recycled aggregates, having very high mechanical, physical and elastic properties, by adding silica fume and a superplasticizer and, on the other hand, to evaluate and compare the maximum compressive strengths using the finite element method.

To achieve these goals, it was decided to divide the work into four stages:

- The first step consisted in optimizing the high-strength concrete (HSC) with 100\% natural aggregates; this was used as reference concrete,

- The second step aimed to optimize the recycled HSC while varying the contents of recycled and natural aggregates,

- The third step was about determining an optimal formulation that could give the maximum strength,

- The last step consisted in comparing the strength obtained with that provided by the finite element method; it also sought to identify the distribution of stresses in the various samples of concrete used.

\section{USED MATERIALS}

\section{Aggregates}

wo types of aggregates were used in this study:

- Natural aggregates (NA)

Class $3 / 8$ and $8 / 15$ crushed limestone gravels were used. These gravels have a specific gravity equal to 2.65 , with $3.70 \%$ impurity and $0.30 \%$ humidity with, and a Los Angeles coefficient of $19.20 \%$. As for sand, it has a specific weight of 2.70 and a fineness modulus of 3.20 .

- Recycled Aggregates

The recycled aggregates (RA) were prepared in the Civil Engineering Laboratory at the University of Djelfa, in Algeria. The following table shows the chemical characteristics of the aggregates.

\begin{tabular}{ccccccccccc}
\hline $\begin{array}{c}\text { Chemical } \\
\text { characteristics }\end{array}$ & $\begin{array}{c}\text { P.A.F. } \\
\%\end{array}$ & $\begin{array}{c}\mathrm{SiO}_{2} \\
\%\end{array}$ & $\begin{array}{c}\mathrm{AI}_{2} \mathrm{O}_{3} \\
\%\end{array}$ & $\begin{array}{c}\mathrm{Fe}_{2} \mathrm{O}_{3} \\
\text { NA }\end{array}$ & $\begin{array}{c}\mathrm{CaO} \\
\mathrm{NaO}\end{array}$ & $\begin{array}{c}\mathrm{MgO}_{3} \\
\mathrm{~K}_{2} \mathrm{O}\end{array}$ & $\begin{array}{c}\mathrm{Na}_{2} \mathrm{O} \\
\%\end{array}$ & $\begin{array}{c}\% \\
\%\end{array}$ \\
RA & 1.47 & 11.35 & 4.59 & 3.52 & 78.89 & 1.10 & 1.22 & 0.41 & 0.13 \\
& - & 47.17 & -0.63 & 0.85 & 49 & 1.02 & 1.30 & 0.50 & - \\
\hline
\end{tabular}

Table 1: Chemical characteristics of aggregates.

Tab. 1 above summarizes the chemical composition of the different aggregates. It was found that the recycled sand included silica and limestone (47\% of silica and $49 \%$ of carbonate) with a small amount of $\mathrm{Alumina}\left(\mathrm{Al}_{2} \mathrm{O}_{3}\right)$ which was due to the presence of cement paste around the sand grains. However, natural aggregates were calcareous in nature, with a fairly high percentage of carbonates (around $78 \%$ ).

Therefore, it can be said that in general recycled aggregates are of a lime-silicate nature. However, this is not always true because it can vary according to the type of the recycled waste. For example, some researchers [20, 21] found out that their recycled aggregates had a rather siliceous nature. 
- Physical and mechanical characteristics:

The water absorption test was carried out according to Standard NF EN 18-554, and the results obtained are summarized in the table below.

\begin{tabular}{ccccccccccc}
\hline $\begin{array}{c}\text { Type of } \\
\text { Aggregate }\end{array}$ & \multicolumn{2}{c}{$\begin{array}{c}\text { Los Angeles } \\
(\%)\end{array}$} & \multicolumn{2}{c}{$\begin{array}{c}\text { Water } \\
\text { absorption (\%) }\end{array}$} & \multicolumn{2}{c}{$\begin{array}{c}\text { Sand equivalent } \\
(\%)\end{array}$} & \multicolumn{2}{c}{$\begin{array}{c}\text { Absolute } \\
\text { density }\end{array}$} & \multicolumn{2}{c}{$\begin{array}{c}\text { Apparent } \\
\text { density }\end{array}$} \\
& NA & RA & NA & RA & NA & RA & NA & RA & NA & RA \\
$8 / 15$ & 19.20 & 31 & 1.35 & 1.1 & 2.48 & 2.45 & - & - & 0.78 & 5.20 \\
$3 / 8$ & 21 & 33 & 1.38 & 1.21 & 2.57 & 2.60 & - & - & 0.92 & 6.30 \\
$0 / 5$ & - & - & 1.20 & 0.9 & 2.89 & 2.80 & 80 & 76 & - & - \\
\hline
\end{tabular}

Table 2: Physical and mechanical characteristics of aggregates.

The findings revealed that the densities decreased as the granular fraction augmented. In addition, natural aggregates and recycled aggregates exhibited nearly the same absolute densities. On the other hand, the apparent densities of recycled aggregates were found lower than those of natural aggregates due to the presence of pores in the recycled aggregates because the concrete waste had a high porosity.

Furthermore, the water absorption test helped to see the difference between the two types of aggregates from the density viewpoint, since the recycled aggregates showed a greater water absorption coefficient (approximately 8\%) than that of natural aggregates (about $2 \%$ ). This difference is primarily attributed to the fact that recycled aggregates had a higher porosity than that of natural aggregates $[4,6]$.

\section{Cement}

The cement (C) used is a Portland cement with high resistance to sulphates (CEM I 42.5 HRS). Its mineralogical composition is such that $\mathrm{C} 3 \mathrm{~S}=60 \%, \mathrm{C} 2 \mathrm{~S}=25.55 \%, \mathrm{C} 3 \mathrm{~A}=2 \%$ and $\mathrm{C} 4 \mathrm{AF}=12.45 \%$. The density of anhydrous cement is $3.23 \mathrm{~g} / \mathrm{cm}^{3}$ and its specific surface is $3880\left(\mathrm{~cm}^{2} / \mathrm{g}\right)$.

\section{Adjuvant}

The adjuvant used is a new generation high-water-reducing superplasticizer of the MEDAFLOW 145 type. It is a solution of polycarboxylates, $31 \%$ dry extract, light pitch color, and $\mathrm{pH}$ between 5 and 6 .

\section{Silica fume}

The actual density of silica fume is $2194\left(\mathrm{Kg} / \mathrm{m}^{3}\right)$ and its Blaine specific surface is greater than $15000\left(\mathrm{~cm}^{2} / \mathrm{g}\right)$.

The chemical compositions of cement and silica fume (SF) used in this study are given in Tab. 3.

\begin{tabular}{cccccccccc}
\hline The samples & $\begin{array}{c}\text { P.A.F. } \\
\%\end{array}$ & $\begin{array}{c}\mathrm{SiO}_{2} \\
\%\end{array}$ & $\begin{array}{c}\mathrm{AI}_{2} \mathrm{O}_{3} \\
\text { Cement }(\mathrm{C})\end{array}$ & $\begin{array}{c}\mathrm{Fe}_{2} \mathrm{O}_{3} \\
\%\end{array}$ & $\begin{array}{c}\mathrm{CaO} \\
\%\end{array}$ & $\begin{array}{c}\mathrm{MgO} \\
\%\end{array}$ & $\begin{array}{c}\mathrm{SO}_{3} \\
\%\end{array}$ & $\begin{array}{c}\mathrm{K}_{2} \mathrm{O} \\
\%\end{array}$ & $\begin{array}{c}\mathrm{Na}_{2} \mathrm{O} \\
\%\end{array}$ \\
Silica fume (SF) & - & 22.31 & 4.39 & 5.52 & 63.89 & 0.80 & 1.11 & 0.41 & 0.09 \\
\hline
\end{tabular}

Table 3: Chemical compositions of the constituents.

The Blaine specific surface area of cement is SSB $=3304\left(\mathrm{~cm}^{2} / \mathrm{gr}\right)$.

The Blaine Specific Surface Area of silica fume is SSB $>20000\left(\mathrm{~cm}^{2} / \mathrm{gr}\right)$.

The abbreviations used:

NC: Normal Concrete

RC: Recycled Concrete

$\mathrm{C}(\mathrm{N}+\mathrm{R})$ : Normal Concrete + Recycled Concrete

HSC: High Strength Concrete

A: Aggregates

NA: Natural Aggregates

RA: Recycled Aggregates

SF: Silica Fume 
Adj: Adjuvant

C: Cement

(W/C): (Water/Cement) ratio

(S/G): (Sand/Gravel) ratio

(W/B): (Water/Binder) ratio

Cs 28D: Compressive strength at 28 Days.

FEM: Finite Element Method.

\section{EXPERIMENTAL STUDY OF THE COMPOSITION OF CONCRETE}

\section{Formulation of reference concrete}

enerally, the formulation methods do not all provide the same results, because each of them must simplify the hypotheses and rely only on a few of them. The assumptions are not always the same. Note, however, that none of these hypotheses leads with certainty to an accurate composition. This is certainly due to the fact that the numerous parameters which have an impact on concrete are difficult to evaluate.

With regard to the formulation of the reference concrete, it was decided to use the Baron-Lesage method, but the aggregate content should be known in advance in order to have an optimal mineral skeleton. According to Baron and Lesage [22], the following two assumptions must be respected:

- For a fixed dosage of cement and water at the beginning (fixed ratio W/C), the most workable and compact concrete is the one that is the most compact with an optimal skeleton.

- The optimal dosage of aggregates does not depend on the contents of water and cement.

It is worth noting that in order to achieve the optimal composition of concrete, several parameters, such as the cement content, water content and aggregate content ( $/ \mathrm{G}=$ Sand/Gravel) should be considered. Therefore, in order to simplify our study and satisfy the hypotheses of the method, only the $(\mathrm{S} / \mathrm{G})$ ratio was varied. The cement dosage and the ratio (W/C) were kept unchanged at the beginning.

According to Gorisse [23], the optimal ratio $(\mathrm{S} / \mathrm{G})$ is between 0.50 and 0.83 . In the present work, seven values of this ratio were selected and tested (step: 0.05) for the purpose of obtaining seven different compositions. The Abrams cone sag, corresponding to the values of the ratio $(S / G)=0.50,0.55,0.60,0.65,0.70,0.75$, and 0.80 , was measured for each composition.

\begin{tabular}{|c|c|c|c|c|c|c|}
\hline \multirow{2}{*}{ Types of concrete } & \multirow{2}{*}{$\begin{array}{c}\mathrm{C} \\
\left(\mathrm{kg} / \mathrm{m}^{3}\right)\end{array}$} & \multicolumn{3}{|c|}{$\mathrm{A}\left(\mathrm{kg} / \mathrm{m}^{3}\right)$} & \multirow{2}{*}{$\begin{array}{c}\mathrm{W} \\
\left(\mathrm{L} / \mathrm{m}^{3}\right)\end{array}$} & \multirow{2}{*}{$\mathrm{W} / \mathrm{B}$} \\
\hline & & $8 / 15$ & $3 / 8$ & $0 / 5$ & & \\
\hline NC $(100 \%)$ & 350 & 905 & 200 & 670 & 192.5 & 0.55 \\
\hline $\mathrm{RC}(100 \%)$ & 350 & 905 & 200 & 670 & 245 & 0.70 \\
\hline$(70 \% \mathrm{NA}+30 \% \mathrm{RA})$ & 350 & 905 & 200 & 670 & 210 & 0.60 \\
\hline$(50 \% \mathrm{NA}+50 \% \mathrm{RA})$ & 350 & 905 & 200 & 670 & 227.5 & 0.65 \\
\hline
\end{tabular}

Table 4: Optimal composition of reference concrete.

The compressive strength at 28 days with these types of concrete are presented in the Fig. 1.

\section{Formulation of the concretes under study}

Once the reference concrete was prepared, a formulation method was established in order to find the optimal composition of the high performance concretes (HPC). It should be noted that the formulation method adopted for the mixture of constituents entering into the composition of high performance concrete is the one that was developed by Aitcin [2] at the University of Sherbrooke. This is a simple and practical method. It consists in combining the empirical results and those obtained using the absolute volume method. The amount of water contained in the superplasticizer is considered to be part of the amount of mixing water.

The data used for the optimal formulation which gave the maximum strength with acceptable workability for one cubic meter of concrete are presented in the Tab. 5. 


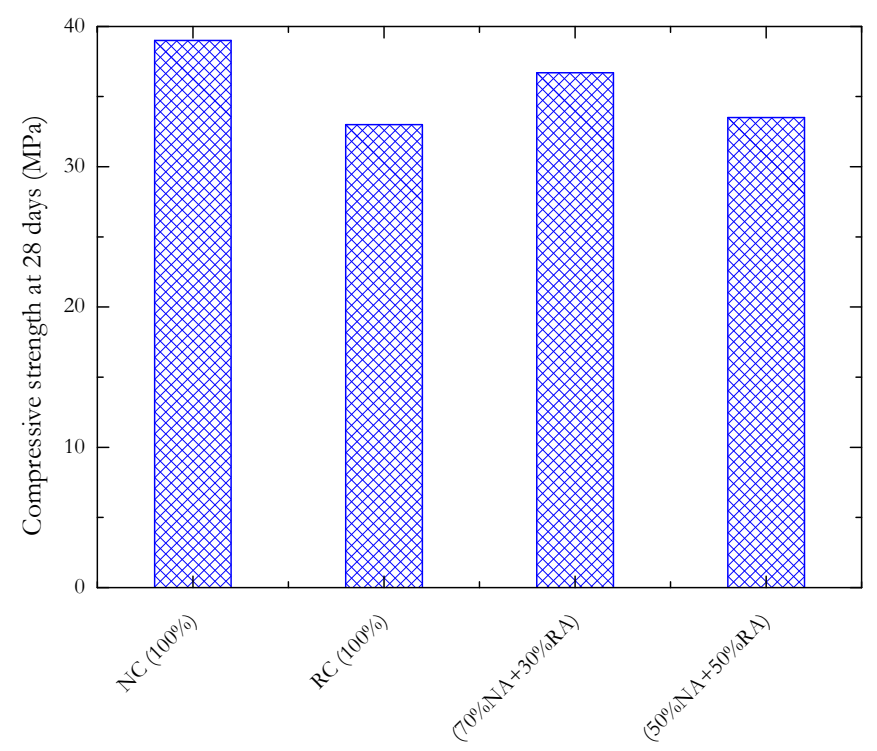

Figure 1: The compressive strength at 28 days of reference concrete.

\begin{tabular}{|c|c|c|c|c|c|c|c|c|c|}
\hline \multirow{2}{*}{ Types of concrete } & \multirow{2}{*}{$\begin{array}{c}\mathrm{C} \\
\left(\mathrm{kg} / \mathrm{m}^{3}\right)\end{array}$} & \multicolumn{3}{|c|}{$\mathrm{A}\left(\mathrm{kg} / \mathrm{m}^{3}\right)$} & \multirow{2}{*}{$\begin{array}{l}\text { SF } \\
(\%)\end{array}$} & \multirow{2}{*}{$\begin{array}{l}\text { Adj. } \\
(\%)\end{array}$} & \multirow{2}{*}{$\mathrm{W} / \mathrm{B}$} & \multirow{2}{*}{$\begin{array}{l}\text { Sagging } \\
(\mathrm{cm})\end{array}$} & \multirow{2}{*}{$\begin{array}{l}\text { Fresh } \\
\text { density }\end{array}$} \\
\hline & & $8 / 15$ & $3 / 8$ & $0 / 5$ & & & & & \\
\hline $\mathrm{NC}+\mathrm{SF}$ & 450.70 & 950 & 200 & 670 & 60.2 & 10.5 & 0.30 & 5.0 & 2567 \\
\hline $\mathrm{RC}+\mathrm{SF}$ & 522.46 & 950 & 200 & 670 & 70.4 & 14.2 & 0.37 & 5.7 & 2389 \\
\hline$(70 \% \mathrm{NA}+30 \% \mathrm{RA}+\mathrm{SF})$ & 472.13 & 950 & 200 & 670 & 65.6 & 11.7 & 0.32 & 4 & 2465 \\
\hline$(50 \% \mathrm{NA}+50 \% \mathrm{RA}+\mathrm{SF})$ & 484.60 & 950 & 200 & 670 & 72.3 & 13.4 & 0.35 & 3 & 2332 \\
\hline
\end{tabular}

Table 5: Composition of concrete mixes.

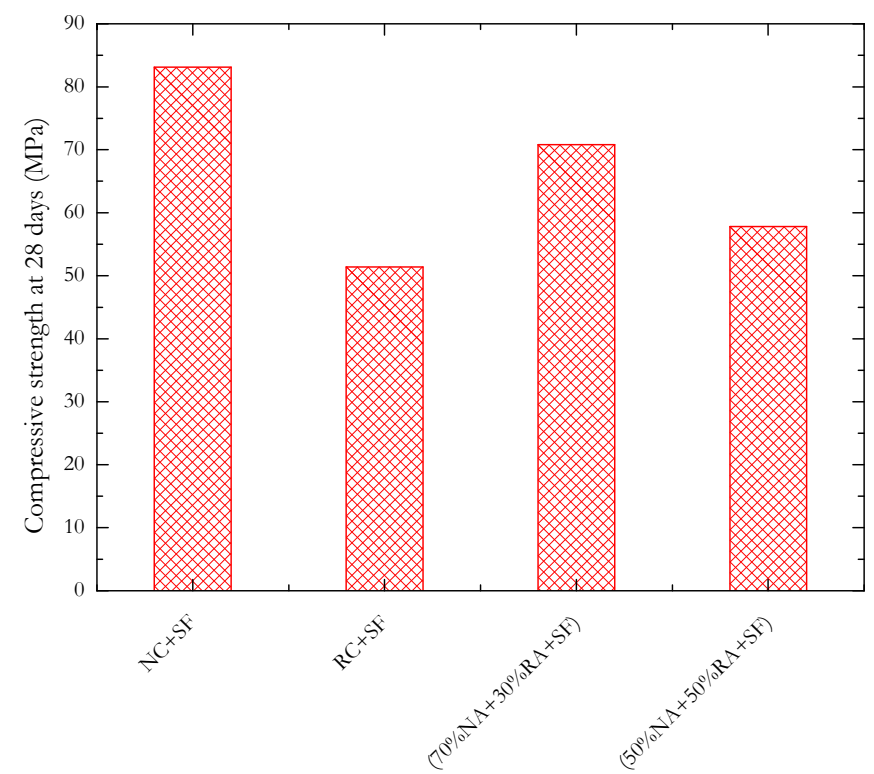

Figure 2: The compressive strength at 28 days of concrete mixes.

Fig. 2 shows the compressive strength at 28 days obtained with this optimal formulation. 


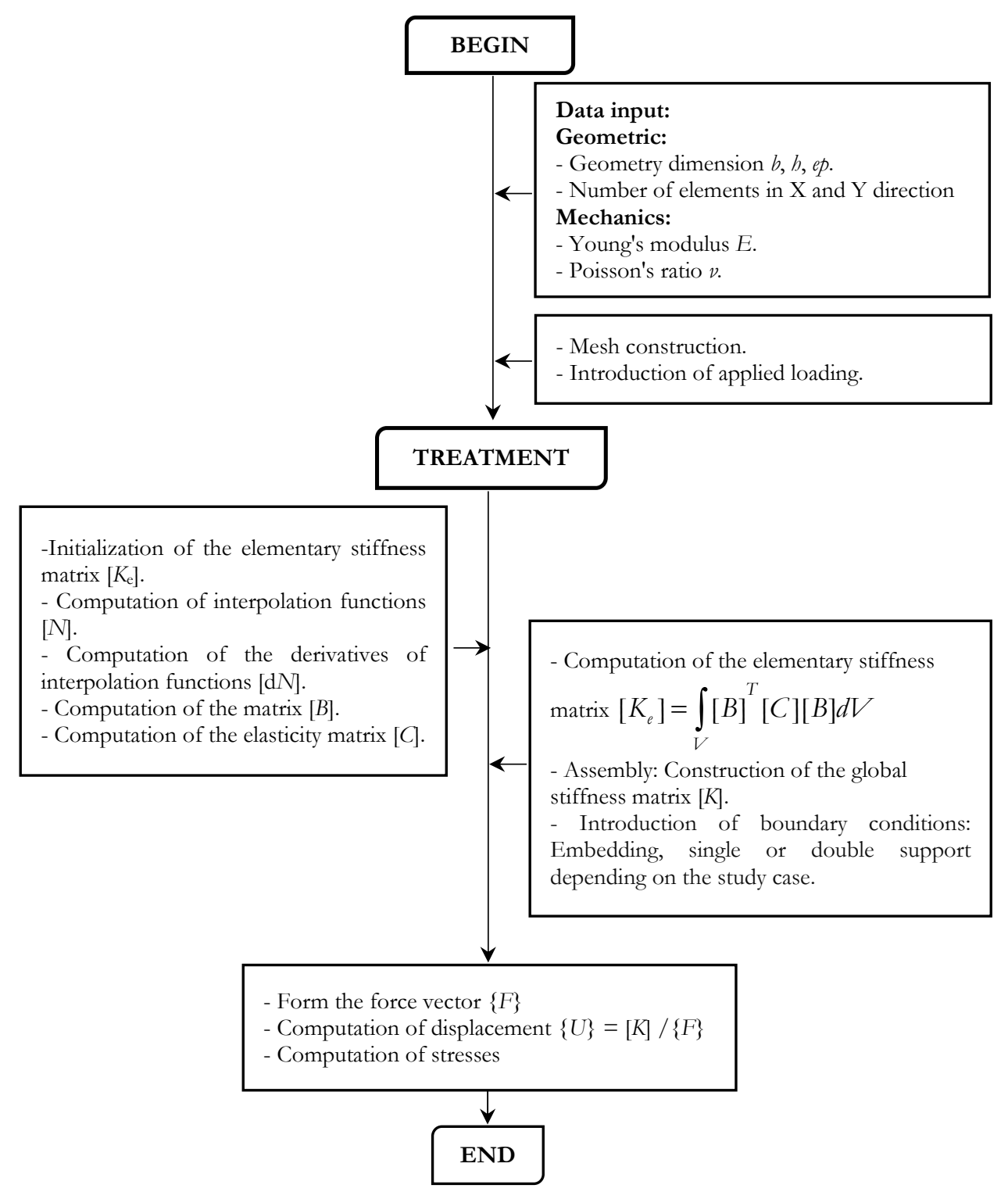

Figure 3: Flowchart of the numerical simulation model.

\section{Discussion and interpretation}

The table above shows that:

- It is possible to manufacture high strength concretes with a compressive strength exceeding $70 \mathrm{MPa}$ (at 28 days) and adequate plasticity, provided that the recycled aggregates are used up to $30 \%$ of the total amount of aggregates in ordinary high-strength concrete.

- Partial substitution of natural aggregates with recycled aggregates for the manufacture of the new concrete offers a new aggregate resource and allows saving natural materials.

- The findings were encouraging since the strength drop of concrete incorporating recycled gravel only does not exceed $17 \%$ for a target characteristic strength of $70 \mathrm{MPa}$.

These results confirm the trend evoked by the antecedent studies of Revilla-Cuesta et al. [25], and Masood et al. [26], their researches is presented into recycled concrete aggregate properties and the mix-design of the self-compacting concretes that contain them, as well as relevant results on the fresh state (workability, rheology), the hardened state (compressive strength, splitting tensile and flexural strength, modulus of elasticity, density, and porosity), durability (resistance to aggressive agents), long-term properties of concrete (shrinkage, creep), and structural elements manufactured with self- 
compacting concrete containing recycled concrete aggregate. The results under review reaffirm that the incorporation of recycled concrete aggregate can produce a suitable self-compacting recycled concrete, on the basis of careful designs that are essential for successful performance.

\section{NUMERICAL STUDY OF CONCRETE SAMPLES}

\section{Modeling by the finite element method}

7 he finite element approximation was programmed under MATLAB [27] for the finite element modeling of concrete specimens. It is represented by the organization chart in Fig. 3.

\section{Numerical application}

The samples investigated in the present work were modeled and evaluated using our finite element calculation code. These are concrete elements of width $b=10 \mathrm{~cm}$, height $H=10 \mathrm{~cm}$ and thickness $e_{p}=10 \mathrm{~cm}$, as shown in Fig. 4 (a), and plane strain conditions are adopted. In the design procedure, it was decided to apply a compression loading similar to that used in the experimental part with a quadrangle mesh density of $100 \times 100$ elements for all types of concrete (Fig. 4 (b)).

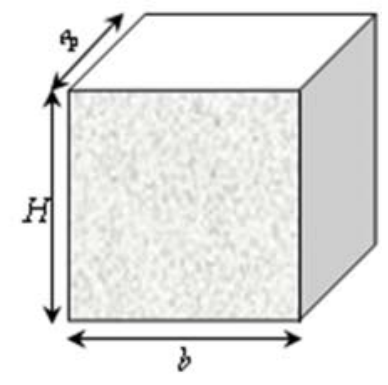

(a)

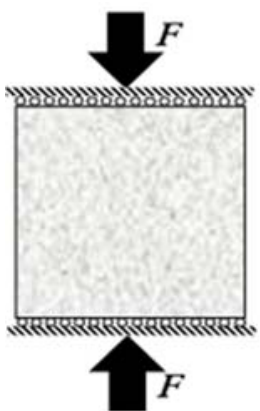

(b)

Figure 4: (a) Geometric configuration of the concrete samples studied, (b) Modeled sample.

Several types of concrete were prepared and investigated in this study. Their mechanical characteristics are summarized in the following table:

\begin{tabular}{lcc}
\hline Types of concrete & $\begin{array}{c}\text { Young's } \\
\text { Modulus E(MPa) }\end{array}$ & $\begin{array}{c}\text { Poisson's } \\
\text { ratio } v\end{array}$ \\
NC $(100 \%)$ & 29000 & 0.20 \\
RC $(100 \%)$ & 24000 & 0.19 \\
$(70 \% \mathrm{NA}+30 \% \mathrm{RA})$ & 27000 & 0.20 \\
$(50 \% \mathrm{NA}+50 \% \mathrm{RA})$ & 25000 & 0.20 \\
$(\mathrm{NA}+\mathrm{SF})$ & 46000 & 0.25 \\
$(\mathrm{RA}+\mathrm{SF})$ & 38000 & 0.23 \\
$(70 \% \mathrm{NA}+30 \% \mathrm{RA}+\mathrm{SF})$ & 42000 & 0.24 \\
$(50 \% \mathrm{NA}+50 \% \mathrm{RA}+\mathrm{SF})$ & 39000 & 0.22 \\
\hline
\end{tabular}

Table 6: Mechanical properties of concretes used in this study.

\section{Results and discussion}

The finite element method (FEM) was programmed and applied to the previously prepared specimens. The results obtained were compared with those provided by the experimental study for the purpose of highlighting the performance of the developed program. 
Fig. 5 displays the results of the comparison between the experimental compressive strengths and those predicted numerically by the finite element method (FEM), at 28 days, for all types of concrete studied.

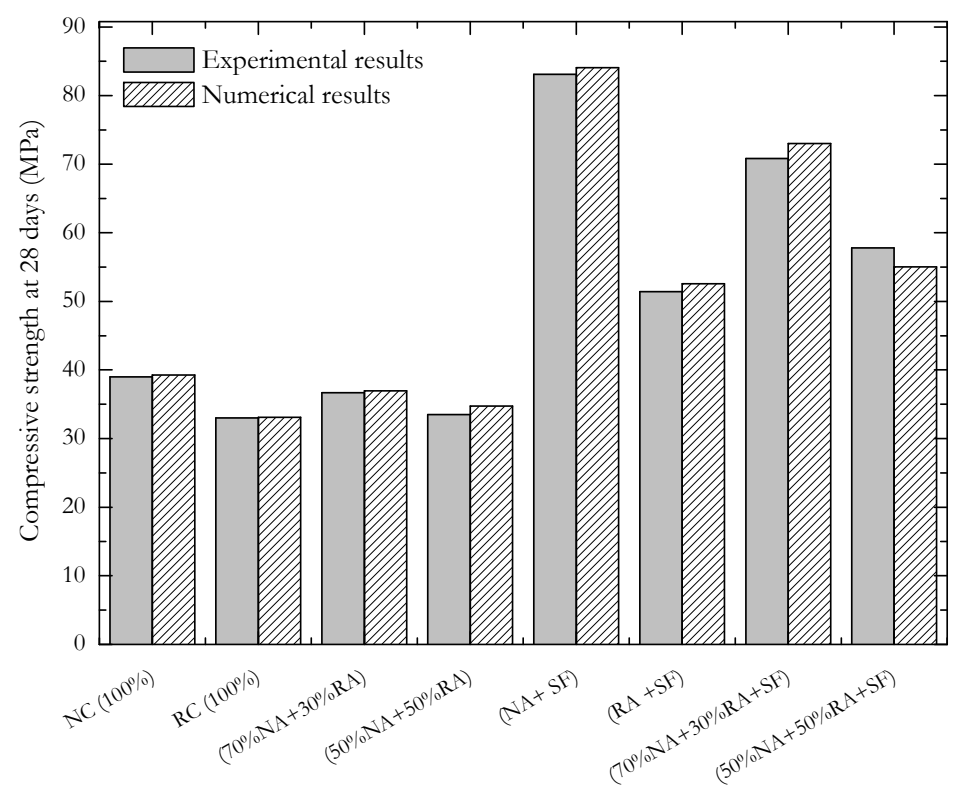

Figure 5: Experimental and numerical compressive strength values at 28 days.

It is quite clear that the compressive strength values obtained at 28 days using our finite element calculation code are in good agreement with those resulting from the experimental tests. Consequently, the data obtained for the compressive strength are quite satisfactory and encouraging.

In order to better understand the distribution of compressive stresses in our concrete samples, the evolution of these stresses was presented for each type of concrete as follows:

(NC $(100 \%), \mathrm{RC}(100 \%),(70 \% \mathrm{NA}+30 \% \mathrm{RA}),(50 \% \mathrm{NA}+50 \% \mathrm{RA}),(\mathrm{NA}+\mathrm{SF}),(\mathrm{RA}+\mathrm{SF}),(70 \% \mathrm{NA}+30 \% \mathrm{RA}+$ $\mathrm{SF}),(50 \% \mathrm{NA}+50 \% \mathrm{RA}+\mathrm{SF}))$, and which are shown in Figs. 6 (a), (b), (c), (d), (e), (f), (g), (h), respectively.

Figs. 6 (a), (b), (c), (d), (e), (f), (g) and (h) present the mapping of the equivalent stress field resulting from numerical simulations using the finite element method (FEM). The distribution of stress is symmetrical about the loading application point. The stress field is maximal at the center of the test specimen. However, the mapping shows the presence of stress concentrations (circled in black in Fig. 6) in the loading application regions which are located at the edge of the specimens. These concentrations were in fact expected due to the presence of the compressive loading at the edge of the specimens. Furthermore, this mapping also showed that the addition of 30\% natural aggregates along with silica fume in the concrete makes it possible to achieve a better distribution of stresses compared to normal concrete.

\section{CONCLUSIONS}

he experimental results obtained indicate that:

- It is quite possible to manufacture a highly resistant concrete, by the partial substitution of natural 1 aggregates with recycled aggregates $(70 \% \mathrm{NA}+30 \% \mathrm{RA})$, with a compressive strength of about $70.80 \mathrm{MPa}$ at 28 days. This value is not too far from that of concrete incorporating natural aggregates only $(100 \% \mathrm{NA})$; its compressive strength was found approximately equal to $83 \mathrm{MPa}$ for the same age. These findings are attributed to the fact that the super plasticizer was very effective in reducing the water-to-binder (W/B) ratio below 0.30. In addition, the use of additions, such as the finely ground silica fume, considerably helped to make the cement paste denser and to further reduce the amount of water, especially that the cement used contains a very small amount of Tricalcium aluminate (CA3).

- Recycled aggregates could be used up to $30 \%$ of the total amount of aggregates for most environments. If recycled sand is used, then the amount used should be less than $30 \%$. 


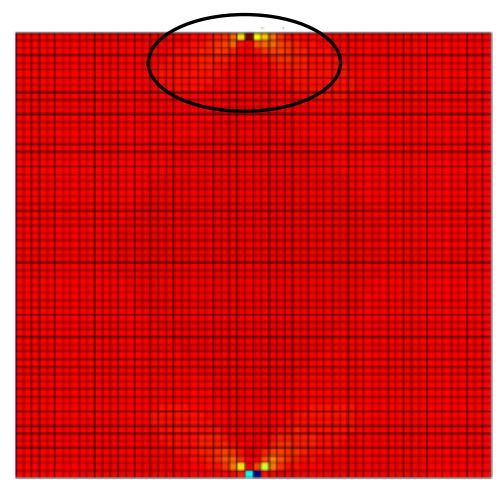

(a)

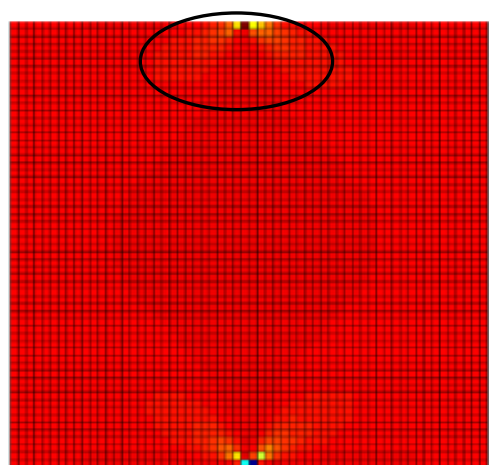

(c)

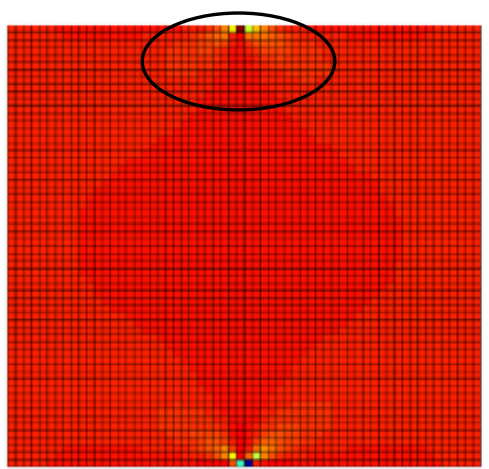

(e)

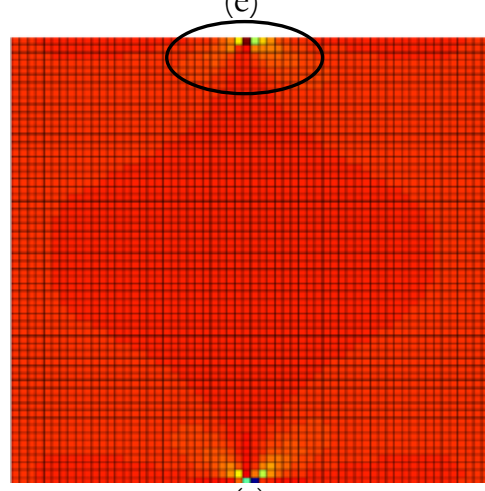

(g)
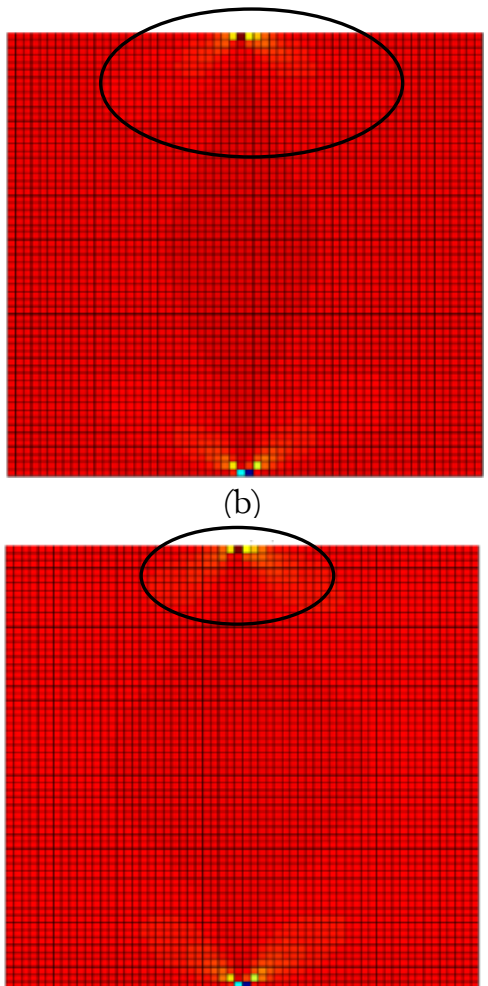

(d)

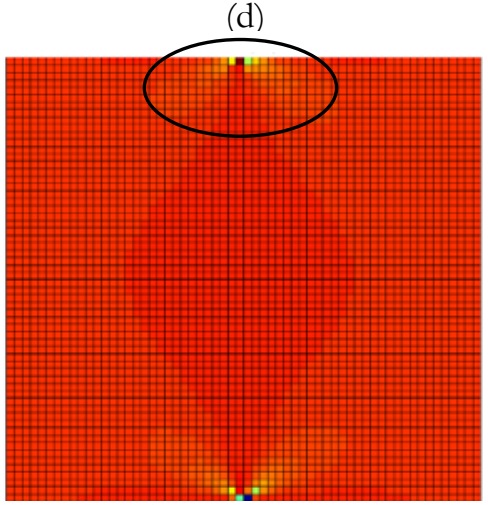

$(\mathrm{f})$

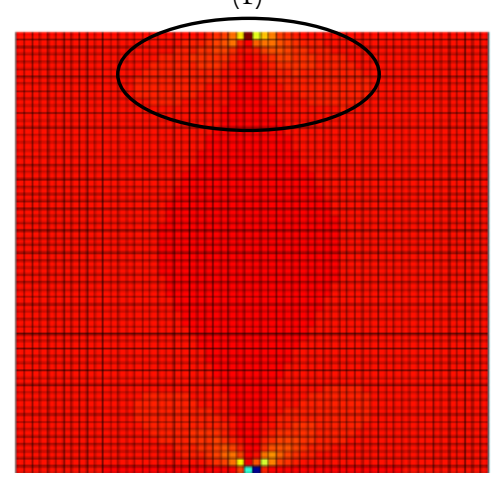

(h)

Figure 6: Distribution of compressive stresses in the samples using MATLAB [27]: (a) NC (100\%), (b) RC (100\%), (c) (70\% NA+ $30 \% \mathrm{RA}),(\mathrm{d})(50 \% \mathrm{NA}+50 \% \mathrm{RA}),(\mathrm{e})(\mathrm{NA}+\mathrm{SF})$, (f) (RA + SF), (g) $(70 \% \mathrm{NA}+30 \% \mathrm{RA}+\mathrm{SF})$, and $(\mathrm{h})(50 \% \mathrm{NA}+50 \% \mathrm{RA}+$ $\mathrm{SF}$. 
- Moreover, good workability can easily be achieved despite the low ratio $(\mathrm{W} / \mathrm{B})=0.35$ thanks to the good quality superplasticizer (Media Flow 145) used. It is useful to remember that this superplasticizer has fairly high rheological and mechanical performance.

- The use of recycled aggregates is of paramount importance from the environmental point of view. This allows getting rid of the materials resulting from the demolition of old buildings and the destruction of structures following natural disasters.

- Moreover, this study allowed us to model the concrete samples prepared, using the finite element method.

- A simple comparison helped to confirm the good correlation between the results obtained by our calculation code and those obtained by the experimental study, for all types of concrete. It can therefore be concluded that the addition of $30 \%$ of recycled aggregates and silica fume into concrete allows achieving a better distribution of stresses in comparison with ordinary concrete.

\section{REFERENCES}

[1] Ministère de L'aménagement du Territoire et de L'Environnement (MATE), Algeria.

[2] Tayeh, B. A., Al Saffar, D. M. and Alyousef, R. (2020). The utilization of recycled aggregate in high performance concrete: a review. J. of Mat. Res. and Tech., 9(4), pp. 8469-8481. DOI: 10.1016/j.jmrt.2020.05.126.

[3] Ali, A. A. M., Zidan, R. S. and Ahmed, T. W. (2020). Evaluation of high-strength concrete made with recycled aggregate under effect of well water. Case Stu. in Const. Mat., 12, e00338. DOI:10.1016/j.cscm. 2020.e00338.

[4] Jin, R., Li, B., Elamin, A., Wang, S., Tsioulou, O. and Wanatowski, D. (2018). Experimental investigation of properties of concrete containing recycled construction wastes. Int. J. of Civ. Eng., 16(11), pp. 1621-1633.

DOI: $10.1007 / \mathrm{s} 40999-018-0301-4$.

[5] Guo, H., Shi, C., Guan, X., Zhu, J., Ding, Y., Ling, T. C., Zhang, H. and Wang, Y. (2018). Durability of recycled aggregate concrete-a review. Cem. and conc. comp., 89, pp. 251-259. DOI: 10.1016/j.cemconcomp.2018.03.008.

[6] Verian, K. P., Ashraf, W. and Cao, Y. (2018). Properties of recycled concrete aggregate and their influence in new concrete production. Res. Conserv. and Recyc., 133, pp. 30-49. DOI:10.1016/j.resconrec.2018.02.005.

[7] Siempu, R. and Pancharthi, R. K. (2017). Bond characteristics of concrete made of recycled aggregates from building demolition waste. Mag. of Conc. Res., 69(13), pp. 665-682. DOI:10.1680/jmacr.16.00400.

[8] Zhang, Y., Luo, W., Wang, J., Wang, Y., Xu, Y., \& Xiao, J. (2019). A review of life cycle assessment of recycled aggregate concrete. Const. and Build. Mat., 209, pp. 115-125. DOI: 10.1016/j.conbuildmat.2019.03.078.

[9] Abid, S. R., Nahhab, A. H., Al-aayedi, H. K. and Nuhair, A. M. (2018). Expansion and strength properties of concrete containing contaminated recycled concrete aggregate. Case Stud. in Constr. Mat., 9, pp. e00201.

DOI: $10.1016 /$ j.cscm.2018.e00201.

[10] Lu, C., Wang, W., Zhou, Q., Wei, S. and Wang, C. (2020). Mechanical behavior degradation of recycled aggregate concrete after simulated acid rain spraying. Jour. of Clea. Produc., 262, pp. 121237. DOI: $10.1016 /$ j.jclepro.2020.121237.

[11] Deshpande, N., Londhe, S., and Kulkarni, S. (2014). Modeling compressive strength of recycled aggregate concrete by Artificial Neural Network, Model Tree and Non-linear Regression. Int. J. of Sust. Bui. Env., 3(2), pp. 187-198. DOI: 10.1016/j.ijsbe.2014.12.002.

[12] Khademi, F., Akbari, M., and Jamal, S. M. M. (2015). Prediction of compressive strength of concrete by data-driven models. I-Manager's J Civ Eng, 5, pp. 16.

[13] Nitka, M. and Tejchman, J. (2015). Modelling of concrete behaviour in uniaxial compression and tension with DEM. Granu. Mat., 17(1), pp. 145-164. DOI: 10.1007/s10035-015-0546-4.

[14] Berrezoug Zidani, M., Belakhdar, K. and Tounsi, A., Adda Bedia, E. (2015). Finite element analysis of initially damaged beams repaired with FRP plates. Compo. struc., 134, pp. 429-439. DOI: 10.1016/j.compstruct.2015.07.124.

[15] Peng, Y., Chu, H., and Pu, J. (2016). Numerical simulation of recycled concrete using convex aggregate model and base force element method. Adv. in Mat. Scien. and Eng., 2016. DOI: 10.1155/2016/5075109.

[16] Havlásek, P. (2020). Numerical modeling of axially compressed circular concrete columns. Eng. Struc., 227, pp. 111445. DOI: $10.1016 /$ j.engstruct.2020.111445.

[17] Pradhan, K. K. and Chakraverty, S. (2019). Chapter Four-Finite element method. In Computational structural mechanics, Academic Press, pp. 25-28. 
[18] Baaser, H. (2010). Development and Application of the Finite Element Method based on MatLab. Springer Science \& Business Media.

[19] Tekkaya, A.E. and Soyarslan, C. (2018). Finite Element Method. In: Int. Academy for Production Engineering, Chatti S., Tolio T. (eds) CIRP Encyc. of Prod. Eng. Springer, Berlin, Heidelberg. DOI:10.1007/978-3-642-35950-7_16699-3

[20] Xiao, J. (2018). Recycled aggregate concrete structures, Springer-Verlag Berlin Heidelberg, pp. 65-98. DOI: $10.1007 / 978-3-662-53987-3$.

[21] Babu, V. S., Mullick, A. K., Jain, K. K. and Singh, P. K. (2015). Strength and durability characteristics of high-strength concrete with recycled aggregate-influence of processing. J. of Sust. Cem.-Bas. Mat., 4(1), pp. 54-71. DOI: $10.1080 / 21650373.2014 .976777$.

[22] Baron, J. (1997). Les additions normalisées pour béton, Ecole française du béton, édition Eyrolles.

[23] Gorisse, D., Festa, J. (1998). Nouveau guide du béton et de ses constituants, Huitième édition, Edition Eyrolles, France.

[24] Aitcin, P.C. (2001). Bétons haute performance, Edition Eyrolles, Paris.

[25] Revilla-Cuesta, V., Skaf, M., Faleschini, F., Manso, J. M. and Ortega-López, V. (2020). Self-compacting concrete manufactured with recycled concrete aggregate: An overview. Jour. of Clea. Produc., 262, pp. 121362. DOI: $10.1016 /$ j.jclepro.2020.121362.

[26] Masood, B., Elahi, A., Barbhuiya, S. and Ali, B. (2020). Mechanical and durability performance of recycled aggregate concrete incorporating low calcium bentonite. Constru. and Build. Mat., 237, pp. 117760. DOI: $10.1016 /$ j.conbuildmat.2019.117760.

[27] MATLAB (1984). Script language with a development environmental for numerical calcul, Version 16.0, MathWorks, California, United States.

\section{ANNEX}

\section{FEM Modeling}

In order to model the concrete samples, the finite element approximation is used [12]. We consider a quadrilateral element (Fig. A.1) the element is defined by four nodes in natural coordinates $(\xi, \eta)$. The coordinates are interpolated and given as follows [15]:

$$
u=\sum_{i=1}^{4} N_{i} u_{i} \quad v=\sum_{i=1}^{4} N_{i} v_{i}
$$

Where $u, v$ represents the displacements fields at any point of the element and $u_{i}, v_{i}$; the nodal displacements.

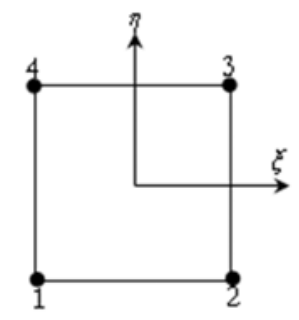

Figure A.1. Quadrilateral Q4 element in natural coordinates $(\xi, \eta)$.

$N_{i}$ represents the standard interpolation functions which are given by:

$$
\begin{aligned}
& N_{1}(\xi, \eta)=l_{1}(\xi) l_{1}(\eta)=\frac{1}{4}(1-\xi)(1-\eta) \\
& N_{2}(\xi, \eta)=l_{2}(\xi) l_{1}(\eta)=\frac{1}{4}(1+\xi)(1-\eta)
\end{aligned}
$$




$$
\begin{aligned}
& N_{3}(\xi, \eta)=l_{2}(\xi) l_{2}(\eta)=\frac{1}{4}(1+\xi)(1+\eta) \\
& N_{4}(\xi, \eta)=l_{1}(\xi) l_{2}(\eta)=\frac{1}{4}(1-\xi)(1+\eta)
\end{aligned}
$$

In matrix form:

$$
\left[N_{i}\right]^{T}=\frac{1}{4}\left[\begin{array}{c}
(1-\xi)(1-\eta) \\
(1+\xi)(1-\eta) \\
(1+\xi)(1+\eta) \\
(1-\xi)(1+\eta)
\end{array}\right]
$$

The derivatives of the interpolation functions $N_{i}$ are:

$$
\left[\frac{\partial N_{i}}{\partial \xi}\right]^{T}=\frac{1}{4}\left[\begin{array}{c}
-(1-\eta) \\
(1-\eta) \\
(1+\eta) \\
-(1+\eta)
\end{array}\right], \quad\left[\frac{\partial N_{i}}{\partial \eta}\right]^{T}=\frac{1}{4}\left[\begin{array}{c}
-(1-\xi) \\
-(1+\xi) \\
(1+\xi) \\
(1-\xi)
\end{array}\right]
$$

These derivatives are transformed by a function $F(x, y)$ with respect to $\xi$ and $\eta$ :

$$
\left\{\begin{array}{l}
\frac{\partial F}{\partial \xi} \\
\frac{\partial F}{\partial \eta}
\end{array}\right\}=\left\{\begin{array}{l}
\frac{\partial F}{\partial x} \frac{\partial x}{\partial \xi}+\frac{\partial F}{\partial y} \frac{\partial y}{\partial \xi} \\
\frac{\partial F}{\partial x} \frac{\partial x}{\partial \eta}+\frac{\partial F}{\partial y} \frac{\partial y}{\partial \eta}
\end{array}\right\}=\left[\begin{array}{ll}
\frac{\partial x}{\partial \xi} & \frac{\partial y}{\partial \xi} \\
\frac{\partial x}{\partial \eta} & \frac{\partial y}{\partial \eta}
\end{array}\right]\left\{\begin{array}{l}
\frac{\partial F}{\partial x} \\
\frac{\partial F}{\partial y}
\end{array}\right\}=[J]\left\{\begin{array}{l}
\frac{\partial F}{\partial x} \\
\frac{\partial F}{\partial y}
\end{array}\right\}
$$

where $J$ is the Jacobian operator, connecting the natural and global coordinates. The derivatives with respect to the global coordinates can be found as follows:

$$
\left\{\begin{array}{l}
\frac{\partial F}{\partial x} \\
\frac{\partial F}{\partial y}
\end{array}\right\}=[J]^{-1}\left\{\begin{array}{l}
\frac{\partial F}{\partial \xi} \\
\frac{\partial F}{\partial \eta}
\end{array}\right\}
$$

The stiffness matrix is then obtained by:

$$
[K]=\int_{V}[B]^{T}[C][B] d V
$$

where $[B]$ is the strain matrix derived from the interpolation functions:

$$
[B]=\left[\begin{array}{cc}
\frac{\partial N_{i}}{\partial x} & 0 \\
0 & \frac{\partial N_{i}}{\partial y} \\
\frac{\partial N_{i}}{\partial x} & \frac{\partial N_{i}}{\partial y}
\end{array}\right], \quad\left\{\begin{array}{c}
\frac{\partial N_{i}}{\partial x} \\
\frac{\partial N_{i}}{\partial y}
\end{array}\right\}=[J]^{-1}\left\{\begin{array}{c}
\frac{\partial N_{i}}{\partial \xi} \\
\frac{\partial N_{i}}{\partial \eta}
\end{array}\right\}
$$


$[C]$ is the elasticity matrix:

$$
\begin{aligned}
& {[C]=\frac{E}{1-v^{2}}\left[\begin{array}{ccc}
1 & -v & 0 \\
-v & 1 & 0 \\
0 & 0 & 2(1+v)
\end{array}\right] \text {, in plane strains }} \\
& {[C]=\frac{E}{(1+v)(1-2 v)}\left[\begin{array}{ccc}
1-v & v & 0 \\
v & 1-v & 0 \\
0 & 0 & (1-2 v) / 2
\end{array}\right] \text {, in plane stresses }}
\end{aligned}
$$

The volume of the element $d V$ is given by:

$$
d V=h \cdot \operatorname{det} J \cdot d \xi . d \eta
$$

where $\operatorname{det} J$ is the determinant of the Jacobian matrix and $b$ the thickness of the element.

The surface $d \xi . d \eta$ at the point $(\xi, \eta)$ of the reference element is transformed into the surface $d A$ at the point $(x((\xi, \eta)), y((\xi$, च))) of the natural element.

Were:

$$
d A=\operatorname{det} J \cdot d \xi . d \eta
$$

The integral in the stiffness matrix on the real element is:

$$
[K]=\int_{V}[F] \cdot d V
$$

Therefore, becomes on the reference element:

$$
[K]=\int_{A} h \cdot[F] \cdot d A
$$

Taking:

$$
[F]=[B]^{T}[C][B]
$$

The integral in the stiffness matrix is then calculated numerically by Gaussian quadrature in two dimensions. In the fournode element, we can use a $2 \times 2$ numerical integration for exact integration.

$$
\int_{-1}^{1} \int_{-1}^{1} F(\xi, \eta) \cdot d \xi . d \eta=\sum_{i=1}^{p} \sum_{j=1}^{q} w_{i} w_{j} F\left(\xi_{i}, \eta_{j}\right)
$$

where $p, q$ are the number of integration points in the directions $\xi, \eta$, respectively, and $w_{i}, w_{j}$ are the corresponding weights. The stiffness matrix can be calculated using $2 \times 2$ Gauss points as:

$$
\begin{aligned}
& {\left[K_{e}\right]=\int_{A} h \cdot[B]^{T}[C][B] \cdot d A=\int_{-1}^{1} \int_{-1}^{1} h \cdot[B]^{T}[C][B] \operatorname{det}[J] \cdot d \xi \cdot d \eta} \\
& =h \cdot \sum_{i=1}^{2} \sum_{j=1}^{2}[B]^{T}[C][B] \cdot \operatorname{det}[J] \cdot w_{i} w_{j}
\end{aligned}
$$

